\title{
ANÁLISE DE ROTAS PARA O ESCOAMENTO DE COMMODITIES SOB A ÓTICA DA CAPACIDADE DOS PORTOS BRASILEIROS
}

\author{
Adonis Carneiro da Silva \\ Instituto Militar de Engenharia \\ Praça General Tibúrcio, 80, Urca, Rio de Janeiro - RJ \\ adoniscarneiro@ime.eb.br \\ Orivalde Soares da Silva Júnior \\ Universidade/Instituição \\ Praça General Tibúrcio, 80, Urca, Rio de Janeiro - RJ \\ orivalde@ime.eb.br
}

\begin{abstract}
RESUMO
A revolução verde introduziu diversas iniciativas tecnológicas que possibilitaram transformar as práticas agrícolas e que aumentaram significativamente a produção de alimentos no mundo. Esta inserção de tecnologias mostrou-se muito aliada dos polos produtores brasileiros, onde a safras, principalmente de grãos, batem recorde de produções ano após ano, mesmo com os períodos de recessão econômica nacional. Entretanto, o planejamento e a infraestrutura dos transportes brasileiros não atendem a crescente demanda de deslocamentos, sobretudo no caso das exportações. Este trabalho propõe uma nova ótica para analisar o planejamento do fluxo da produção de commodities brasileiras, focando na infraestrutura já existente nos portos e utilizando métodos de otimização para encontrar soluções rotas ótimas. A aplicação deste estudo se dá no caso da produção de soja no estado do Mato Grosso.
\end{abstract}

Palavra-chave: Commodities; Portos; Rotas; Transportes; Exportações.

\begin{abstract}
The green revolution has introduced a number of technological initiatives to transform agricultural practices and increase food production in the world. This insertion of technologies proved to be very allied with the Brazilian producer poles, where the harvests, especially the grains, beat the recordings of productions year after year, the same with the economies of national economic recession. However, planning and infrastructure of Brazilian transport do not increase the demand for displacement, especially in the case of exports. This paper approved a new approach to analyze or plan the production flow of Brazilian commodities, focusing on the existing infrastructure in ports and using optimization methods to find optimal route solutions. The application of this study does not provide any case of soy production in the state of Mato Grosso.
\end{abstract}

Keywords: Commodities; Ports; Routes; Transportation; Exports. 


\section{Como Citar:}

SILVA, Adonis Carneiro da; SILVA JÚNIOR, Orivalde Soares da. Análise de rotas para o escoamento de commodities sob a ótica da capacidade dos portos brasileiros. In: SIMPÓSIO DE PESQUISA OPERACIONAL E LOGÍSTICA DA MARINHA, 19., 2019, Rio de Janeiro, RJ. Anais [...]. Rio de Janeiro: Centro de Análises de Sistemas Navais, 2019.

\section{INTRODUÇÃO}

O processo de escoamento da produção de commodities para os portos brasileiros é um constante desafio para os tomadores de decisão. Diversos fatores são levados em conta quando a se trata de transportar granéis sólidos para os terminais portuários, tais como: tempo de viagem, custo, distância, flexibilidade, infraestrutura existente, capacidade, demanda, confiabilidade, impacto ambiental etc.

Este estudo tem como objetivo apresentar uma proposta de procedimento para a avaliação de rotas eficientes para o escoamento de commodities brasileiras, levando em conta a situação atual dos portos no país. A logística brasileira enfrenta vários gargalos, sobretudo no momento de escoamento de grandes quantidades de commodities. A Figura 1, por exemplo, mostra a relevância de alguns portos para o escoamento de grãos provenientes da região Centro-Oeste do Brasil.

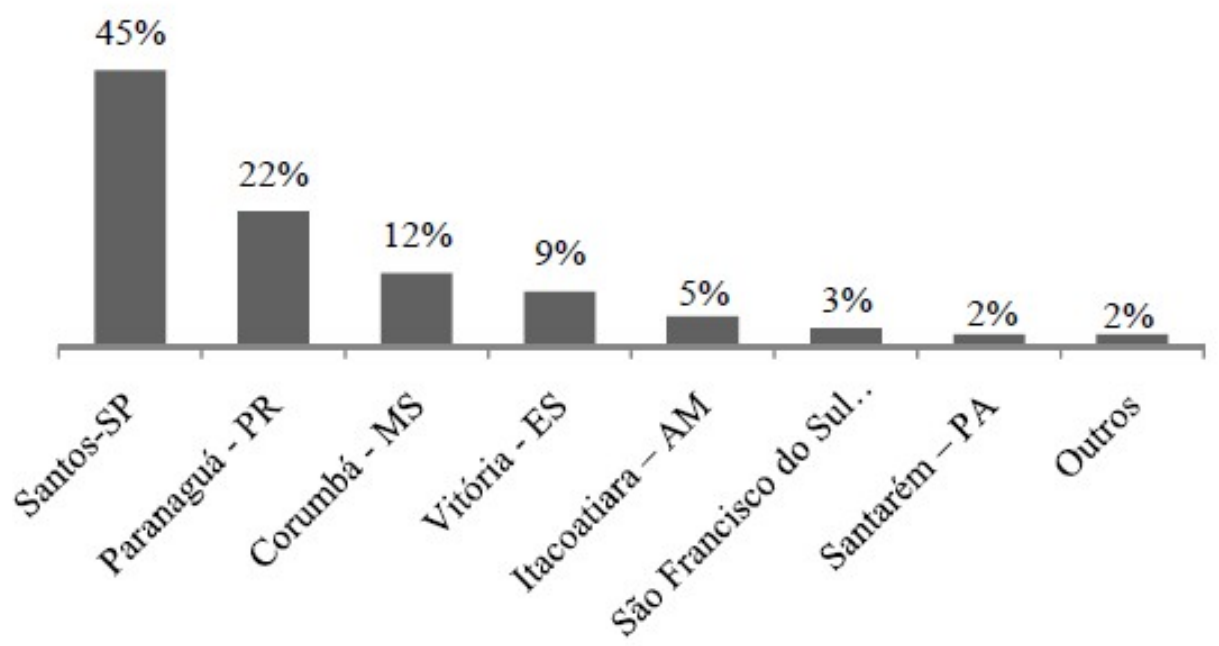

Figura 1 - Relevância de portos para escoamento de granéis do Centro-Oeste [1]

A constante queixa de produtores, os quais dependem do bom funcionamento do setor de transportes, para aumento da produção, leva a realização de análises sobre diversas perspectivas, com o intuito de otimizar o funcionamento deste ciclo no país. Através desses estudos contemplados, inúmeros cenários podem ser gerados, no entanto deverá haver um critério que classifique as opções mais viáveis para o investimento, então partindo desse ponto apresentar ferramentas que contribuam pelo menos em uma parcela para a decisão é considerado importante.

A pesquisa envolvida para a aplicação do estudo é delimitada a partir dos indicadores públicos e gratuitos disponíveis em sítios governamentais, selecionados e relacionados ao desempenho das alternativas de rota de transporte. 


\section{REVISÃO BIBLIOGRÁFICA}

Commodities são produtos de baixo e médio valor agregado possuem o frete como parcela significativa da composição do preço final, portanto é fundamental saber otimizar os custos de transportes destes produtos.

De acordo com [2], o principal produto brasileiro destinado à exportação no período de janeiro a dezembro de 2017 foi a soja, com 11,81\%. o minério de ferro é o segundo produto mais exportado pelo país, com $8,82 \%$. Em terceiro lugar são os óleos brutos do petróleo (7,64\%), seguidos do açúcar de cana (4,15\%).

Segundo [3], o transporte de commodities para os portos era feito à base de burros e escravos até meados de 1850, quando as leis contrárias à escravidão começaram a serem implementadas. A partir daí começaram a surgir as primeiras ferrovias, que com o passar dos anos não se sustentaram, devido principalmente ao incentivo à construção de rodovias, sobretudo a partir da década de 1950.

Com a matriz brasileira bastante depende de rodovias, surgem entraves logísticos e competitivos para o escoamento da produção brasileira. A necessidade de equilibrar a matriz de transportes, dando espaço para ferrovias, hidrovias e cabotagem, faz com que inúmeros estudos em transportes abordem a questão das commodities. Foi proposto por [1] uma análise de alternativas de rotas de escoamento destes produtos através da Lógica Fuzzy. O estudo de [4] abordou o peso destas mercadorias no planejamento de novos traçados ferroviários. Já [5] otimizou o traçado de uma possível rodovia brasileira com os locais produtores de diversas commodities.

\section{MODELO PROPOSTO}

O modelo aqui apresentado consiste em analisar a demanda de commodities sob a ótica da capacidade dos complexos portuários brasileiros, e não apenas sob o valor do frete. Os portos brasileiros apresentam diferentes níveis de composição quanto à capacidade possível de atender cada tipo de carga. Granéis sólidos, granéis líquidos, contêineres, carga geral possuem diferentes valores de capacidade suportada em cada porto brasileiro.

Como ocorre de terminais ficarem sobrecarregados, ao passo que outros ficarem ociosos, ao invés de despender recursos em novas infraestruturas portuárias, seria de grande valia otimizar a utilização de estruturas já existentes em outras localidades.

Para isso, segundo [6], faz se uso de um modelo de fluxo em redes, classificado em fluxo de produtos, e denominado de problema de transportes. Este é frequentemente em aplicações de programação matemática em problemas de logística, pois tipicamente envolve decisões como: volumes transportados entre localidades, níveis de produção dos pontos de oferta e níveis de estoque.

Abaixo é ilustrado o modelo, onde o objetivo é minimizar o custo do frete do transporte das commodities, respeitando as restrições de oferta das localidades de origem e de demanda do porto solicitado.

$$
\operatorname{Minimizar}_{x} z=\sum_{i, j} c_{i j} x_{i j}
$$

Sujeito a:

$$
\begin{aligned}
& \sum_{j} x_{i j} \leq a_{i}, \forall i \\
& \sum_{j} x_{i j} \geq b_{j}, \forall j
\end{aligned}
$$




$$
x_{i j} \geq 0, \forall i, j
$$

Em que:

i: $\quad$ localidades de origem;

j: $\quad$ portos de destino;

$a_{i}$ : $\quad$ oferta de commodity no local i;

$b_{j}$ : $\quad$ demanda do porto j de acordo com sua capacidade;

$\mathrm{c}_{\mathrm{ij}}$ : $\quad$ custo unitário para transportar a mercadoria entre origem $i$ e porto $j$;

$x_{i j}$ : $\quad$ quantidade transportada entre a origem $i$ e o porto $j$;

\section{APLICAÇÃO DO MODELO}

Para a aplicação do modelo proposto a soja foi escolhida como commodity, devido a sua importante participação na composição do PIB agropecuário brasileiro. Segundo [7], o país é o segundo maior produtor do grão no mundo, com aproximadamente 117 milhões de toneladas anuais, ficando apenas atrás dos Estados Unidos, com 119,5 milhões de toneladas anuais. Os estados brasileiros que detém maiores participações na produção são o Mato Grosso, o Paraná e o Rio Grande do Sul, com 32, 19 e 17 milhões de toneladas, respectivamente.

Como o estado do Mato Grosso apresenta uma produção de destaque, porém uma malha de transporte aquém da necessária, este será o caso escolhido no âmbito de localidade. Segundo [8], [9] e [10] para o estudo das localidades produtoras de granéis, o estado é dividido em sete regiões, I - Noroeste, II - Norte, III - Nordeste, IV - Médio-Norte, V Oeste, VI - Centro-Sul, VII - Sudeste, como ilustra a Figura 2.

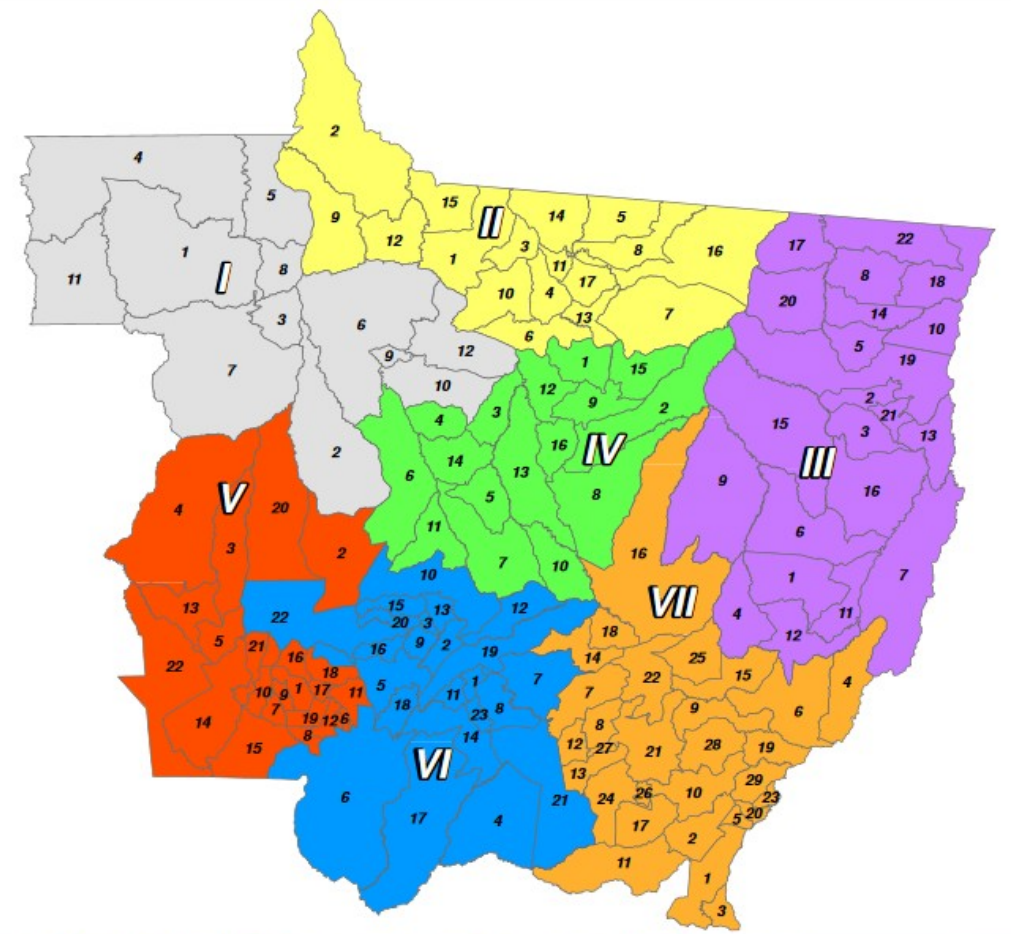

Figura 2 - Divisão das regional do estado do Mato Grosso. Fonte: IMEA (2019)

Os portos para onde é destinada a produção de soja no Brasil estão localizados em todas as regiões do país. No caso da produção mato-grossense, os principais portos de destino estão localizados nos seguintes complexos: Amazonas-Santarém (portos de Itacoatiara, Santarém, Miritituba e Santana), Maranhão-Vila do Conde (portos de Itaqui e 
Vila do Conde), Espírito Santo (porto de Vitória), São Paulo (porto de Santos) e Paraná-São Francisco do Sul (portos de Paranaguá e São Francisco do Sul). A Figura 3 ilustra o caminho da safra de soja brasileira, contendo rodovias, ferrovias, hidrovias e portos.

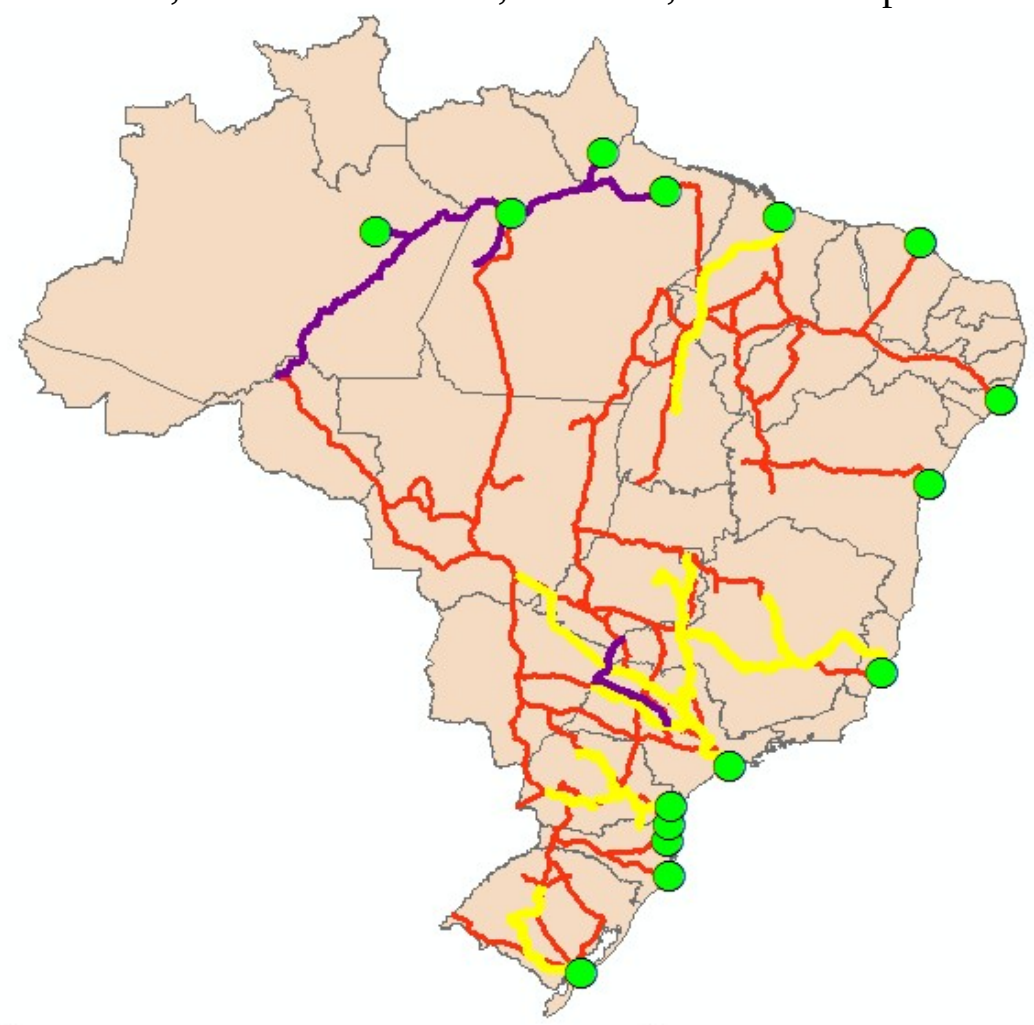

Figura 3 - Rotas de escoamento da safra de soja brasileira. Fonte: Elaborado pelo autor

Através de [11], foi feito o levantamento da capacidade de granéis sólidos de cada complexo portuário para onde a soja mato-grossense é levada. A tabela 1 mostra situação atual e a previsão de demanda para o ano de 2042 para este tipo de carga, em milhões de toneladas.

Tabela 1 - Capacidade atual e demanda futura de granéis sólidos em portos brasileiros

\begin{tabular}{lrrr}
\hline Complexo & Capacidade Atual & Demanda em 2042 & Déficit futuro \\
\hline Amazonas Santarém & 35 & 35,7 & 0,7 \\
Maranhão Vila do Conde & 260,3 & 344,2 & 83,9 \\
Espírito Santo & 241 & 215,9 & não há \\
São Paulo & 62,3 & 105,7 & 43,4 \\
Paraná São Francisco do Sul & 66,2 & 33 & 33,2 \\
\hline
\end{tabular}

Como determinado porto não recebe apenas soja como granel sólido, mas sim vários outros também, como café e milho por exemplo, e as procedências não são apenas do Mato Grosso, faz-se uma normalização da capacidade atual com a demanda de exportação de soja do estado do Mato Grosso e com a porcentagem de participação da soja na exportação de granéis sólidos. A tabela 2 ilustra os valores obtidos, juntamente com os valores de frete entre as localidades, dados em $\mathrm{R} \$ /$ toneladas e calculados a partir da distância entre as localidades.

Tabela 2 - Ofertas e demandas de soja entre regiões e portos (em milhões de toneladas)

\begin{tabular}{|c|c|c|c|c|c|}
\hline $\begin{array}{l}\text { Amazo- } \\
\text { nas San- }\end{array}$ & $\begin{array}{l}\text { Maranhão- } \\
\text { Vila do Con- }\end{array}$ & $\begin{array}{c}\text { Espírito } \\
\text { Santo }\end{array}$ & São Paulo & $\begin{array}{l}\text { Paraná-São } \\
\text { Francisco do }\end{array}$ & Oferta \\
\hline
\end{tabular}




\begin{tabular}{llrrrrrr}
\hline & \multicolumn{1}{c}{ tarém } & \multicolumn{1}{c}{ de } & & \multicolumn{3}{c}{ Sul } \\
\hline I & Noroeste & 170 & 300 & 309 & 189 & 215 & 1,31 \\
II & Norte & 190 & 270 & 300 & 185 & 211 & 0,78 \\
III & Nordeste & 210 & 222 & 247 & 160 & 186 & 3,31 \\
IV & Médio-Norte & 156 & 280 & 275 & 163 & 189 & 6,56 \\
V & Oeste & 138 & 285 & 275 & 160 & 186 & 2,12 \\
VI & Centro-Sul & 170 & 260 & 270 & 155 & 181 & 1,44 \\
VI & & & & & & \\
I & Sudeste & 200 & 240 & 250 & 149 & 175 & 3,88 \\
& Demanda & 1,05 & 7,83 & 7,25 & 1,87 & 0,99 & \\
\hline
\end{tabular}

O modelo foi aplicado para a otimização do transporte de soja das regiões do estado localidades para os portos nacionais, utilizando o software Microsoft Excel 2016 e o software AIMMS.

\section{ANÁLISE DOS RESULTADOS}

A partir da utilização dos softwares mencionados, obtemos como valores ótimos os listados na Tabela 3, em milhões de toneladas.

Tabela 3 - Distribuição da produção de soja aos portos segundo otimização do software AIMMS

\begin{tabular}{|c|c|c|c|c|c|c|}
\hline & & $\begin{array}{l}\text { Amazo- } \\
\text { nas San- } \\
\text { tarém }\end{array}$ & $\begin{array}{c}\text { Maranhão- } \\
\text { Vila do Con- } \\
\text { de }\end{array}$ & $\begin{array}{c}\text { Espírito } \\
\text { Santo }\end{array}$ & São Paulo & $\begin{array}{l}\text { Paraná-São } \\
\text { Francisco do } \\
\text { Sul }\end{array}$ \\
\hline 1 & Noroeste & & & & 0,9 & \\
\hline II & Norte & & 0,78 & & & \\
\hline III & Nordeste & & 3,31 & & & \\
\hline IV & Médio-Norte & & & 6,56 & & \\
\hline v & Oeste & 1,05 & & & 0,08 & 0,99 \\
\hline VI & Centro-Sul & & 0,55 & & 0,89 & \\
\hline VI & & & & & & \\
\hline I & Sudeste & & 3,19 & 0,69 & & \\
\hline
\end{tabular}

Com base nestes dados pode-se constatar que a solução ótima para o problema recomenda fortemente os portos que possuem maior capacidade de comportar granéis sólidos. Para a produção realizada na região Oeste do estado recomenda-se o escoamento através dos portos do norte brasileiro, através dos rios da Amazônia, e por meio dos portos de Santos e do sul do país.

A safra de soja proveniente da região Médio-Norte é destinada exclusivamente ao porto de Vitória no Espírito Santo. Já a soja vinda do Noroeste do estado tem o porto de Santos como destino único. Para as produções do Norte e Nordeste mato-grossense, o complexo Maranhão-Vila do Conde é a melhor opção.

O Centro-Sul e o Sudeste têm sua soja voltada para o Porto de Itaqui (MA) e Vila do Conde (PA), mas o primeiro também tem como opção o Porto de Santos, e o segundo o Porto de Vitória.

A Figura 4 ilustra como ficaria essa nova disposição em porcentagem, contrastando com a Figura 1. 


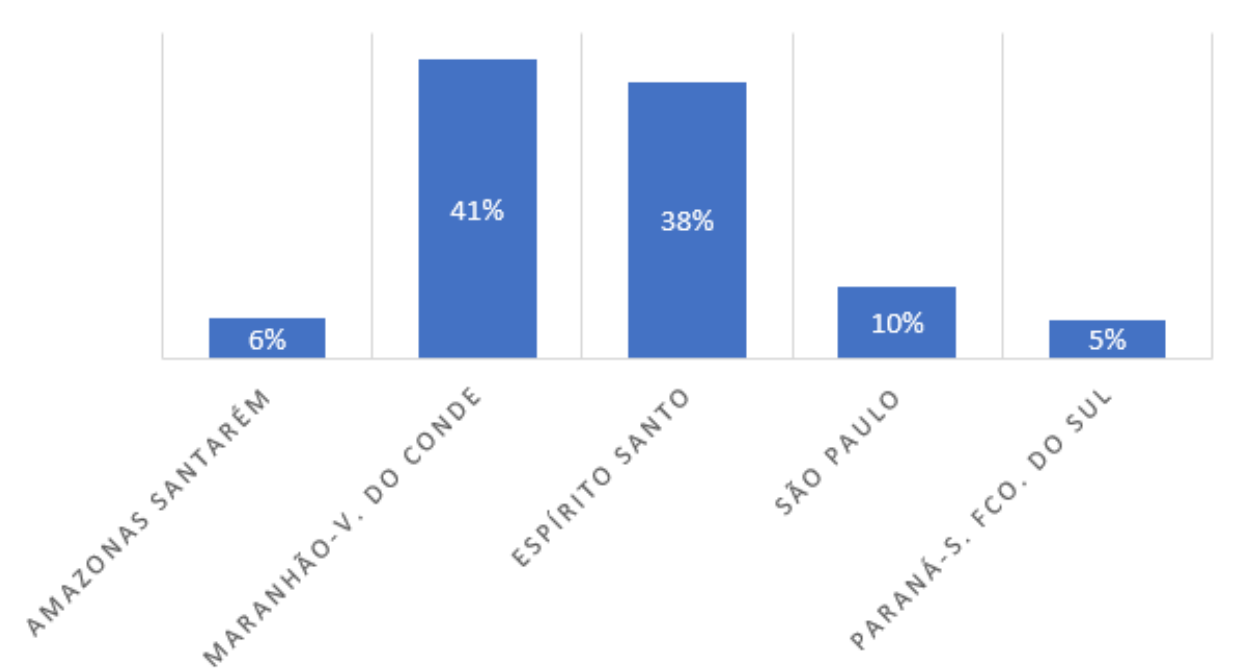

Figura 4 - Relevância atribuída aos portos para escoamento de soja do Centro-Oeste segundo ótica do trabalho. Fonte: Elaborado pelo autor

\section{CONCLUSÕES}

A abordagem e resultados deste estudo colocam um olhar sobre a necessidade de avaliar outras diretrizes no transporte de carga no Brasil, além do frete. Fatores como capacidade, flexibilidade, tempo, confiabilidade, impacto ambiental, precisam ser relevantes no planejamento e operação da movimentação de cargas pelo país.

É evidente que a preferência histórica pelo transporte rodoviário traduz muitos números deste gráfico, como a preferência por portos do sul e sudeste brasileiro. Entretanto sobre outras óticas é necessário saber otimizar infraestruturas já existentes que estão ociosas e aproveitar o largo potencial que outras regiões brasileiras possuem para o escoamento de grãos.

Para estudos futuros, recomenda-se realizar a aplicação deste método para outros casos de commodities e localidades, com o intuito de compará-lo com a situação atual das rotas e capacidade dos portos no escoamento da produção brasileira e importação de bens estrangeiros.

\section{REFERÊNCIAS BIBLIOGRÁFICAS}

[1] ASSIS, T. F. D. ANÁLISE DE ALTERNATIVAS DE TRANSPORTE DE COMMODITIES NO BRASIL: O CASO DA SOJA NO ESTADO DO MATO GROSSO. Rio de Janeiro: [s.n.], 2015.

[2] BRASIL. Balança Comercial Brasileira: Acumulado do Ano. Ministério da Economia, 2018. Disponivel em: <http://www.mdic.gov.br/index.php/comercio-exterior/estatisticas-de-comercioexterior/balanca-comercial-brasileira-acumulado-do-ano>. Acesso em: 03 abr. 2019.

[2] ANTAQ. Estatísticas. Agência Nacional de Transportes Aquaviários, 2019. Disponivel em: $<$ http://portal.antaq.gov.br/index.php/estatisticas/>. Acesso em: 01 maio 2019.

[3] SALOMÃO. E. História. 1ª ed. São José dos Campos: Editora Poliedro, v. 2, 2011.

[4] NÓBREGA, R. A. D. A. N. et al. Inteligência geográfica para avaliação de propostas de projeto de concessão de corredores ferroviários. Revista Transportes. 29 Dezembro 2016.

[5] LOPES, E. E. Determinação de Diretrizes de Traçado Geométrico de Obras Lineares Utilizando Análise Multicriterio. Florianópolis. 2015 
[6] GOLDBARG, M. C. OTIMIZAÇÃo COMBINATÓRIA E PROGRAMAÇÃo LINEAR. Rio de Janeiro: Elsevier, 2005.

[7] EMBRAPA. Embrapa Soja. Embrapa, 2018. Disponivel em:

$<$ https://www.embrapa.br/soja/cultivos/soja1/dados-economicos>. Acesso em: 05 maio 2019.

[8] IMEA. Estudos customizados. IMEA, 2019. Disponivel em: $<$ http://www.imea.com.br/imea-site/ estudos-customizados>. Acesso em: 16 abr. 2019.

[9] IMEA. Indicadores. IMEA, 2019. Disponivel em:

$<$ http://www.imea.com.br/imea-site/indicadores>. Acesso em: 20 abr. 2019

[10] IMEA. Relatórios de Mercado. IMEA, 2019. Disponivel em: $<$ http://www.imea.com.br/imeasite/relatorios-mercado>. Acesso em: 20 abr. 2019.

[11]ANTAQ. Estrutura Portuária. Agência Nacional de Transportes Aquaviários, 2017. Disponivel em: $<$ http://portal.antaq.gov.br/wp-content/uploads/2017/02/Estrutura-portu \%C3\%A1ria.pdf $>$. Acesso em: 01 maio 2019. 